Pacific Journal of Mathematics

CONTINUOUSLY VARYING PEAKING FUNCTIONS

ornaess and Steven Krantz 


\title{
CONTINUOUSLY VARYING PEAKING FUNCTIONS
}

\author{
John Erik Fornaess and Steven George Krantz
}

Let $X$ be a compact metric space, $A \subseteq C(X)$ a closed subalgebra. Let $\mathscr{P} \subseteq X$ be the set of peak points for $A$. It is shown that there is a continuous function $\Phi: \mathscr{P} \rightarrow A$ such that $\Phi(x)$ peaks at $x$ for all $x \in \mathscr{P}$.

o. Let $X$ be a compact Hausdorff space, $C(X)$ the continuous functions on $X$ under the uniform norm, and $A$ a closed subspace of $C(X)$ containing 1 . Let $\mathscr{P}$ be the set of peak points for $A$. Clearly if $X$ has more than one point and $x \in \mathscr{P}$ then there are infinitely many functions in $A$ which peak at $x$. Can one construct a function

$$
\Phi: \mathscr{P} \longrightarrow A
$$

so that $\Phi(x)$ peaks at $x$ and $\Phi$ has some regularity properties?

In [4], using the von Neumann selection principle, it was shown that for $X=\overline{\mathscr{D}} \subset \subset C^{n}$ with smooth boundary, $A=A(\mathscr{D})$ (the analytic functions on $\mathscr{D}$ which extend continuously to $\overline{\mathscr{D}}$ ), one can choose $\Phi$ to be measurable. The same argument is valid under much more general circumstances.

In the present note we prove that, for quite general $X$ and for $A$ an algebra, $\Phi$ can be chosen to be continuous. This generalizes results in [1, Theorem 3.1] and [2, Proposition 4].

1. Throughout the discussion, $X$ will be a fixed compact metric space with metric $d$. We let $C(X)$ denote the continuous, complexvalued functions on $X$ with the uniform norm and $A \subseteq C(X)$ will be a closed complex linear subspace. If $x \in X, r>0$, then $B(x, r)=$ $\{t \in X: d(x, t)<r\}$.

Definition. A point $x \in X$ is said to be a peak point for $A$ if there is an $f \in A$ with $f(x)=1$ and, for all $y \in X \sim\{x\},|f(y)|<1$. The function $f$ is said to peak at $x$.

We let $\mathscr{P}(A)$ denote the set of peak points for $A$.

THEOREM. Let $X$ be a compact metric space, $A \subseteq C(X)$ a closed subalgebra (with or without 1 ). Then there is a continuous map

$$
\Phi: \mathscr{P}(A) \longrightarrow A
$$

such that $\Phi(x)$ peaks at $x$ for each $x \in \mathscr{P}(A)$. 
The remainder of the paper is devoted to the proof of the theorem. We proceed via a sequence of lemmas. The plan of the proof is as follows.

For each $k \in\{1,2, \cdots\}$ we will construct a continuous function

$$
\Phi_{k}: \mathscr{P}(A) \longrightarrow A
$$

such that for each $x \in \mathscr{P}(A)$ we have

(i ) $\left\|\Phi_{k}(x)\right\|=1$;

(ii) $\left[\Phi_{k}(x)\right](x)=1$;

(iii) if $t \in X \sim B(x, 1 / k)$ then $\left|\left[\Phi_{k}(x)\right](t)\right| \leqq 1-1 /(k+2)$.

Once the $\left\{\Phi_{k}\right\}$ are constructed, the proof is immediate. For let $\Phi=\sum_{l=1}^{\infty} 2^{-l} \Phi_{l}$. Then $\Phi$ is continuous and for each $x \in \mathscr{P}(A)$ we have $\Phi(x) \in A$ and $[\Phi(x)](x)=1$. Moreover, if $t \neq x$ and $k>1 / d(x, t)$ then

$$
\begin{aligned}
|[\Phi(x)](t)| & \leqq \sum_{l \neq k} 2^{-l}\left|\left[\Phi_{l}(x)\right](t)\right|+\left|2^{-k}\left[\Phi_{l k}(x)\right](t)\right| \\
& \leqq 1-2^{-k}+2^{-k}(1-1 /(k+2))<1 .
\end{aligned}
$$

So $\Phi(x)$ peaks at $x$. Thus it remains to construct the $\Phi_{k}$.

LEMma 1. Let $x_{0} \in \mathscr{P}(A)$. Let $p$ be a strictly positive continuous function on $X$ with $p\left(x_{0}\right)=1$. Then there is an $f \in A$ with $f\left(x_{0}\right)=1$ and $|f(x)| \leqq p(x)$ for all $x \in X$.

Proof. This is a special case of Theorem 12.5 of Gamelin [3], p. 58.

COROLLARY 2. With hypotheses as in Lemma 1, there is a $g \in A$ such that $g\left(x_{0}\right)=1,|g(x)|<p(x)$ for all $x \in X \sim\left\{x_{0}\right\}$.

Proof. Immediate.

Lemma 3. Let $x_{0} \in \mathscr{P}(A)$. Let $\downarrow \in A$ peak at $x_{0}$. There is a $\operatorname{map}$

$$
\Psi: \mathscr{P}(A) \cap\{|\psi(x)|>1 / 2\} \longrightarrow A
$$

so that

(i ) $\Psi(x)$ peaks at $x$ for each $x \in \mathscr{P}(A) \cap\{|\psi(x)|>1 / 2\}$,

(ii) $\Psi\left(x_{0}\right)=\psi$,

(iii) $\Psi$ is continuous at $x_{0}$.

Proof. For each $x \in \mathscr{P}(A) \sim\left\{x_{0}\right\}$ choose, by Corollary 2, a function $\varphi_{x} \in A$ such that $\varphi_{x}(x)=1$ and 
$(*)$

$$
\begin{gathered}
\left|\varphi_{x}(t)\right|<\min \{(2-|\psi(x)|-|\psi(t)|) / 2(1-|\psi(x)|), 1\} \\
\text { for all } t \in X \sim\{x\} .
\end{gathered}
$$

Now for each $x \in \mathscr{P}(A) \cap\{|\psi(x)|>1 / 2\}$ we define $\Psi(x)=\left\{\begin{array}{cl}{\left[2(1-|\psi(x)|) \varphi_{x}+\overline{\operatorname{sgn} \psi(x) \psi}\right] /[2-|\psi(x)|]} & \text { if } x \neq x_{0},|\psi(x)|>1 / 2, \\ \psi & \text { if } x=x_{0} .\end{array}\right.$

Here $\operatorname{sgn} z \equiv z /|z|$, any $z \in C \sim\{0\}$.

Clearly if $x \neq x_{0}$ and $x$ is sufficiently close to $x_{0}$ then $|\psi(x)|>1 / 2$ and we have

$$
\begin{aligned}
\|\Psi(x)-\psi\| \leqq & \|\Psi(x)-\overline{\operatorname{sgn} \psi(x)} \cdot \psi\|+\|\overline{\mid \operatorname{sgn} \psi(x)} \cdot \psi-\psi\| \\
\leqq & \left\|\left[2(1-|\psi(x)|) \varphi_{x}+\overline{\operatorname{sgn} \psi(x)} \cdot \psi\right] /[2-|\psi(x)|]-\overline{\operatorname{sgn} \psi(x)} \cdot \psi\right\| \\
& +\| \psi(1-\overline{\operatorname{sgn} \psi(x))} \| \\
\leqq & \left\{\left[2(1-|\psi(x)|)\left\|\varphi_{x}-\overline{\operatorname{sgn} \psi(x)} \cdot \psi\right\|\right.\right. \\
& +(1-|\psi(x)|)|| \overline{\operatorname{sgn} \psi(x)} \cdot \psi \|||\} /[2-|\psi(x)|]+\mid 1-\overline{\operatorname{sgn} \psi(x) \mid} \\
\leqq & 5(1-|\psi(x)|)+\mid 1-\overline{\operatorname{sgn} \psi(x) \mid} \\
& \longrightarrow 0 \text { as } x \longrightarrow x_{0} .
\end{aligned}
$$

It remains to verify that $\Psi(x)$ peaks at $x$ when $|\psi(x)|>1 / 2$. For such $x$, we have $[\Psi(x)](x)=1$. Further, if $t \neq x$ then by $\left(^{*}\right)$ we have

$$
2(1-|\psi(x)|)\left|\varphi_{x}(t)\right|<2-|\psi(x)|-|\psi(t)|
$$

or

$$
\left|2(1-|\psi(x)|) \varphi_{x}(t)\right|+|\psi(t)|<2-|\psi(x)|
$$

whence

$$
\left|2(1-|\psi(x)|) \varphi_{x}(t)+\overline{\operatorname{sgn} \psi(x)} \psi(t)\right|<2-|\psi(x)|
$$

or

$$
|[\Psi(x)](t)|<1
$$

LeMma 4. Fix a positive integer $k$. There is a sequence $\left\{\Phi_{k}^{j}\right\}_{j=1}^{\infty}$ of functions,

$$
\Phi_{k}^{j}: \mathscr{P}(A) \longrightarrow A
$$

satisfying, for each $z \in \mathscr{P}(A)$ and every $j$,

$$
\begin{aligned}
& \text { (i) }\left\|\Phi_{k}^{j}(x)\right\|=1 ; \\
& \text { (ii) }\left[\Phi_{k}^{j}(x)\right](x)=1 ; \\
& \text { (iii) } \lim _{\supset(A) \ni y \rightarrow x}\left\|\Phi_{k}^{j}(x)-\Phi_{k}^{j}(y)\right\| \leqq 4^{-j} \cdot(1 / k) \text {; }
\end{aligned}
$$


(iv) for every $t \in X \sim B\left(x,\left(1-2^{-j}\right) \cdot(1 / k)\right)$,

$$
\left|\left[\Phi_{k}^{j}(x)\right](t)\right| \leqq(1-2 /(k+2))+\sum_{i=1}^{j} 2^{-i} \cdot(1 /(k+2)) ;
$$

( v ) $\left\|\Phi_{k}^{j}(x)-\Phi_{k}^{j-1}(x)\right\| \leqq 2^{-j} \cdot(1 / k), j \geqq 2$.

Proof. This lemma is the heart of the matter. We construct the $\Phi_{k}^{j}$ inductively on $j$. First consider $j=1$. For each $x \in \mathscr{P}(A)$ construct, by Lemma 1, a function $\varphi_{x} \in A$ which satisfies $\varphi_{x}(x)=1$ and

$$
\left|\varphi_{x}(t)\right| \leqq \min \{1-8 k d(x, t) /(k+2), 1-2 /(k+2)\} .
$$

Using $\psi=\varphi_{x}$, construct a function

$(*)$

$$
\Psi_{x}^{1}: \mathscr{P}(A) \cap\{|\psi(x)|>1 / 2\} \longrightarrow A
$$

satisfying the conclusions of Lemma 3 . Choose $r_{x}^{1}, 0<r_{x}^{1}<1 / 4 k$ so that $t \in B\left(x, r_{x}^{1}\right)$ implies that $\left|\varphi_{x}(t)\right|>1 / 2$ and

$$
\left\|\Psi_{x}^{1}(x)-\Psi_{x}^{1}(t)\right\|<4^{-2} \cdot(1 /(k+2)) .
$$

Now observe that if $y \in B\left(x, r_{x}^{1}\right)$ and $t \notin B(y, 1 / 2 k)$ then

$$
d(x, t) \geqq d(y, t)-d(y, x) \geqq 1 / 4 k .
$$

Therefore for such $y, t$ we have

$$
\begin{aligned}
\left|\left[\Psi_{x}^{1}(y)\right](t)\right| & \leqq\left|\left[\Psi_{x}^{1}(x)(t)\right]\right|+\left|\left[\Psi_{x}^{1}(x)\right](t)-\left[\Psi_{x}^{1}(y)\right](t)\right| \\
& \leqq\left|\varphi_{x}(t)\right|+4^{-2} \cdot(1 /(k+2)) \\
& \leqq(1-2 /(k+2))+2^{-1} \cdot(1 /(k+2))
\end{aligned}
$$

Now since $\mathscr{P}(A)$ is a metric space, it is paracompact ([5], p. 160, Cor. 35). Hence there is a locally finite refinement $\mathscr{C}^{1}=\left\{U_{\omega}^{1}\right\}_{\omega \in \Omega_{1}}$ of the covering $\left\{B\left(x, r_{x}^{1}\right)\right\}_{x \in \mathscr{O}(A)}$ of $\mathscr{P}(A)$. Let $x_{\omega}, \omega \in \Omega_{1}$, be chosen so that $U_{\omega}^{1} \subseteq B\left(x_{\omega}, r_{\omega}^{1}\right)$. Let $B_{\omega}^{1}$ denote $B\left(x_{\omega}, r_{x_{\omega}}^{1}\right)$. We may assume that $\bar{U}_{\omega}^{1} \subseteq B_{\omega}^{1}$. Let $\left\{\chi_{\omega}^{1}\right\}$ be a continuous partition of unity subordinary to $\mathscr{U}^{1}$ and define

$$
\Phi_{k}^{1}=\sum_{\omega \in \Omega} \chi_{\omega}^{1} \Psi_{x_{\omega}}^{1}
$$

Then conclusions (i) and (ii) are immediate. Conclusion (iv) follows from $\left({ }^{* *}\right)$. Conclusion (v) is vacuous for $j=1$. It remains to verify (iii).

Fix $x \in \mathscr{P}(A)$. Then there is a neighborhood $W$ of $x$ and $\left\{\omega_{1}, \cdots, \omega_{m}\right\} \subseteq \Omega_{1}$ so that $W \cap \operatorname{supp} \chi_{\omega} \neq 0$ only if $\omega \in\left\{\omega_{1}, \cdots, \omega_{m}\right\}$. Of course $m$ may depend on $x$. Letting $x_{i}$ denote $x_{\omega_{i}}, i=1, \cdots, m$, we have that 


$$
\begin{aligned}
& \lim _{\mathscr{S}(A) \ni y \rightarrow x} \sup _{\|}\left\|\Phi_{k}^{1}(x)-\Phi_{k}^{1}(y)\right\| \leqq \sum_{i=1}^{m} \lim _{\mathcal{S}(A) \cap W \ni y \rightarrow x} \sup _{W}\left|\chi_{\omega_{i}}^{1}(x)-\chi_{\omega_{i}}^{1}(y)\right|\left\|\Psi_{x_{i}}(y)\right\| \\
& +\sum_{i=1}^{m} \chi_{\omega_{i}}^{1}(x) \lim _{\mathscr{P}(A) \cap W \ni y \rightarrow x} \sup _{x_{i}}\left\|\Psi_{x_{i}}^{1}(x)-\Psi_{x_{i}}^{1}(y)\right\| \\
& \leqq 0+\sum_{i=1}^{m} \chi_{\omega_{i}}^{1}(x) \lim _{\mathscr{P}(A) \cap B_{\omega_{i}} \ni y \rightarrow x}\left\|\Psi_{x_{i}}^{1}(x)-\Psi_{x_{i}}^{1}\left(x_{i}\right)\right\| \\
& +\sum_{i=1}^{m} \chi_{\omega_{i}}^{1}(x) \lim _{\mathscr{A}(A) \cap B_{\omega_{i} \ni y \rightarrow x}}\left\|\Psi_{x_{i}}^{1}\left(x_{i}\right)-\Psi_{x_{i}}^{1}(y)\right\| \\
& \leqq 2 \cdot 4^{-2} /(k+2) \leqq 4^{-1} \cdot(1 / k) \text {. }
\end{aligned}
$$

Now suppose that $\Phi_{k}^{1}, \cdots, \Phi_{k}^{j}$ have been constructed so that (i)-(v) are satisfied. Let $x \in \mathscr{P}(A)$. Using $\psi=\Phi_{k}^{j}(x)$, we construct a function

$$
\Psi_{x}^{j+1}: \mathscr{P}(A) \cap\{|\psi(x)|>1 / 2\} \longrightarrow A
$$

satisfying the conclusions of Lemma 3. Choose $r_{x}^{j+1}, 0<r_{x}^{j+1}<$ $2^{-j-1} \cdot(1 / k)$ so that $t \in B\left(x, r_{x}^{j+1}\right)$ implies that $\left|\left[\Phi_{k}^{j}(x)\right](t)\right|>1 / 2$ and both

$$
\left\|\Psi_{x}^{j+1}(x)-\Psi_{x}^{j+1}(t)\right\| \leqq 4^{-j-2} \cdot(1 /(k+2))
$$

$\left(*^{* *}\right)$ and

$$
\left\|\Phi_{k}^{j}(x)-\Phi_{k}^{j}(t)\right\| \leqq(4 / 3) \cdot 4^{-j} \cdot(1 / k) .
$$

If now $y \in B\left(x, r_{x}^{j+1}\right), t \notin B\left(y,\left(1-2^{-j-1}\right) \cdot(1 / k)\right)$ then

$$
d(x, t) \geqq d(y, t)-d(y, x) \geqq\left(1-2^{-j}\right)(1 / k) .
$$

Hence for such $y, t$ we have

$$
\begin{aligned}
\left|\left[\Psi_{x}^{j+1}(y)\right](t)\right| & \leqq\left|\left[\Psi_{x}^{j+1}(x)\right](t)\right|+\left|\left[\Psi_{x}^{j+1}(x)\right](t)-\left[\Psi_{x}^{j+1}(y)\right](t)\right| \\
& \leqq\left|\left[\Phi_{k}^{j}(x)\right](t)\right|+4^{-j-1} \cdot(1 /(k+2)) \\
& \leqq(1-2 /(k+2))+\sum_{i=1}^{j} 2^{-i} \cdot(1 /(k+2))+2^{-j-1} \cdot(1 /(k+2)) \\
& =(1-2 /(k+2))+\sum_{i=1}^{j+1} 2^{-i} \cdot(1 /(k+2)) .
\end{aligned}
$$

Choose a locally finite refinement $\mathscr{Q}^{j+1}=\left\{U_{\omega}^{j+1}\right\}_{\omega \in \Omega_{j+1}}$ of the covering $\left\{B\left(x, r_{x}^{j+1}\right)\right\}_{x \in \quad(A)}$ of $\mathscr{P}(A)$. Let $\left\{x_{\omega}\right\}_{\omega \in \Omega_{j+1}}$ be chosen so that $U_{\omega}^{j+1} \cong$ $B\left(x_{\omega}, r_{x_{\omega}}^{j+1}\right) \equiv B_{\omega}^{j+1}$, each $\omega \in \Omega_{j+1}$. We may assume that $\bar{U}_{\omega}^{j+1} \subseteq B_{\omega}^{j+1}$. Let $\left\{\chi_{\omega}^{j+1}\right\}$ be a continuous partition of unity subordinate to $\mathscr{U}^{j+1}$. Define

$$
\Phi_{k}^{j+1}=\sum_{\omega \in \Omega_{j+1}} \chi_{\omega}^{j+1} \Psi_{x_{\omega}}^{j+1}
$$

It follows as in the case $j=1$ that (i), (ii), (iii), and (iv) hold. To verify (v) fix $x \in \mathscr{P}(A)$. Let $\omega_{1}, \cdots, \omega_{m}$ satisfy the property that 
$\chi_{\omega}(x) \neq 0$ iff $\omega \in\left\{\omega_{1}, \cdots, \omega_{m}\right\}$. Let $x_{i}$ denote $x_{\omega_{i}}, i=1, \cdots, m$. Then

$$
\begin{aligned}
\left\|\Phi_{l}^{j+1}(x)-\Phi_{k}^{j}(x)\right\| \leqq & \left\|\sum_{l=1}^{m} \chi_{\omega_{l}}^{j+1}(x)\left[\Psi_{x_{l}}^{j+1}(x)-\Psi_{x_{l}}^{j+1}\left(x_{l}\right)\right]\right\| \\
& +\left\|\sum_{l=1}^{m} \chi_{\omega_{l}}^{j+1}(x)\left[\Psi_{x_{l}}^{j+1}\left(x_{l}\right)-\Phi_{k}^{j}\left(x_{l}\right)\right]\right\| \\
& +\left\|\sum_{l=1}^{m} \chi_{\omega_{l}}^{j+1}(x)\left[\Phi_{k}^{j}\left(x_{l}\right)-\Phi_{k}^{j}(x)\right]\right\| \\
\leqq & 4^{-j-2}\left(1 /(k+2)+0+(4 / 3) 4^{-j}(1 / k)\right) \leqq 2^{-j}(1 / k) .
\end{aligned}
$$

The induction is complete.

Lemma 5. For $k \in\{1,2, \cdots\}$ there exist functions

$$
\Phi_{k}: \mathscr{P P}(A) \longrightarrow A
$$

such that

(i ) $\left\|\Phi_{k}(x)\right\|=1$ for all $x \in \mathscr{P}(A)$,

(ii) $\left[\Phi_{l c}(x)\right](x)=1$;

(iii) $\Phi_{k}$ is continuous;

(iv) $\left|\left[\Phi_{k}(x)\right](t)\right| \leqq 1-1 /(k+2)$ for all $x \in \mathscr{P}(A), t \in X \sim B(x, 1 / k)$.

Proof. Let $\Phi_{k}^{j}$ be as in Lemma 4 and define $\Phi_{k}=\lim _{j \cdots \infty} \Phi_{k}^{j}$. That the limit exists follows from (v) of Lemma 4. The conclusions (i)-(iv) of the present lemma now follow from the corresponding parts of Lemma 4.

By the discussion preceding Lemma 1, the proof of the theorem is complete.

REMARK. Our proof yields something more general. Indeed, instead of assuming $X$ to be metric, one need only assume that the relative topology on $\mathscr{S}$ has a $\sigma$-locally finite base. By [5], p. 128, this is equivalent to assuming that $\mathscr{P}$ is metric, hence paracompact, and the proof goes through as before.

The referee has kindly observed that given our Lemma 3 , one can use Theorem $3.1^{\prime \prime}$ of [6] to prove that if $X$ is compact Hausdorff and $A$ is separable then the theorem holds. This is a weaker result than the one outlined in the preceding paragraph. Moreover, the proof using [6] is not essentially shorter than the elementary one presented here, and the construction of $\Phi$ as the unifiorm limit of discontinuous functions has intrinsic interest.

REMARK. It would be interesting to know whether, in the presence of differentiable structure in $X$ and $A$, the peaking functions may be chosen to vary differentiably. 


\section{REFERENCES}

1. E. Bedford and J. E. Fornaess, A construction of peak functions on weakly pseudoconvex domains, Ann. of Math., 107 (1978), 555-568.

2. I. Graham, Boundary behavior of the Caratheodory and Kobayashi metrics on strongly pseudoconvex domains in $\mathrm{C}^{n}$, Trans. Amer. Math. Soc., 207 (1975), 219-240.

3. T. W. Gamelin, Uniform Algebras, Englewood Cliffs, Academic Press, 1969.

4. N.P. Jewell and S. G. Krantz, Toeplitz operators and related function algebras on certain pseudoconvex domains, Trans. Amer. Math. Soc., 252 (1979), 297-312.

5. J. L. Kelley, General Topology, New York, Van Nostrand, 1955.

6. E. Michael, Continuous selections, I, Ann. of Math., 63 (1956), 361-382.

Received October 30, 1978 and in revised form January 8, 1979. The work of the first author was supported in part under NSF Grant No. MCS 78-01488. The work of the second author was supported in part under NSF Grant No. MCS 77-02213.

Princeton University

PRINCETON, NJ 08540

AND

UNIVERSITY OF CALIFORNIA

Los ANGEles, CA 90024 



\title{
PACIFIC JOURNAL OF MATHEMATICS
}

\section{EDITORS}

DONALD BABBITT (Managing Editor)

University of California

Los Angeles, CA 90024

\section{HUGO RossI}

University of Utah

Salt Lake City, UT 84112

C. C. MOORE and ANDREW OGG

University of California

Berkeley, CA 94720

\section{J. DUGUNDJI}

Department of Mathematics University of Southern California Los Angeles, CA 90007

R. FINN and J. Milgram

Stanford University Stanford, CA 94305

\section{ASSOCIATE EDITORS}
E. F. BECKENBACH
B. H. NeUmanN
F. WOLF
K. YosHIDA

\section{SUPPORTING INSTITUTIONS}

\author{
UNIVERSITY OF BRITISH COLUMBIA \\ CALIFORNIA INSTITUTE OF TECHNOLOGY \\ UNIVERSITY OF CALIFORNIA \\ MONTANA STATE UNIVERSITY \\ UNIVERSITY OF NEVADA, RENO \\ NEW MEXICO STATE UNIVERSITY \\ OREGON STATE UNIVERSITY \\ UNIVERSITY OF OREGON
}

\author{
UNIVERSITY OF SOUTHERN CALIFORNIA \\ STANFORD UNIVERSITY \\ UNIVERSITY OF HAWAII \\ UNIVERSITY OF TOKYO \\ UNIVERSITY OF UTAH \\ WASHINGTON STATE UNIVERSITY \\ UNIVERSITY OF WASHINGTON
}

The Supporting Institutions listed above contribute to the cost of publication of this Journal, but they are not owners or publishers and have no responsibility for its content or policies.

Mathematical papers intended for publication in the Pacific Journal of Mathematics should be in typed form or offset-reproduced, (not dittoed), double spaced with large margins. Please do not use built up fractions in the text of the manuscript. However, you may use them in the displayed equations. Underline Greek letters in red, German in green, and script in blue. The first paragraph or two must be capable of being used separately as a synopsis of the entire paper. Please propose a heading for the odd numbered pages of less than 35 characters. Manuscripts, in triplicate, may be sent to any one of the editors. Please classify according to the scheme of Math. Reviews, Index to Vol. 39. Supply name and address of author to whom proofs should be sent. All other communications should be addressed to the managing editor, or Elaine Barth, University of California, Los Angeles, California, 90024.

50 reprints to each author are provided free for each article, only if page charges have been substantially paid. Additional copies may be obtained at cost in multiples of 50 .

The Pacific Journal of Mathematics is issued monthly as of January 1966. Regular subscription rate: $\$ 84.00$ a year (6 Vols., 12 issues). Special rate: $\$ 42.00$ a year to individual members of supporting institutions.

Subscriptions, orders for numbers issued in the last three calendar years, and changes of address should be sent to Pacific Journal of Mathematics, P.O. Box 969, Carmel Valley, CA 93924, U.S.A. Older back numbers obtainable from Kraus Periodicals Co., Route 100, Millwood, NY 10546.

PUBLISHED BY PACIFIC JOURNAL OF MATHEMATICS, A NON-PROFIT CORPORATION

Printed at Kokusai Bunken Insatsusha (International Academic Printing Co., Ltd.). 8-8, 3-chome, Takadanobaba, Shinjuku-ku, Tokyo 160, Japan.

Copyright (C) 1979 by Pacific Journal of Mathematics Manufactured and first issued in Japan 


\section{Pacific Journal of Mathematics}

\section{Vol. 83, No. $2 \quad$ April, 1979}

Patrick Robert Ahern, On a theorem of Hayman concerning the derivative of a

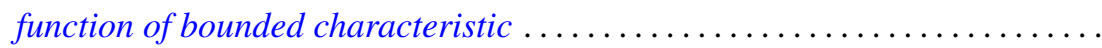

Walter Allegretto, Finiteness of lower spectra of a class of higher order elliptic

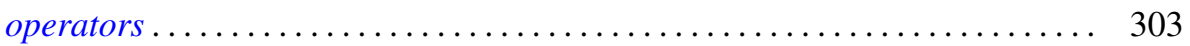

Leonard Asimow, Superharmonic interpolation in subspaces of $C_{c}(X) \ldots \ldots 11$

Steven F. Bellenot, An anti-open mapping theorem for Fréchet spaces . . . . . . . 325

B. J. Day, Locale geometry. . . . . . . . . . . . . . . . . . . . . . . . . . 333

John Erik Fornaess and Steven Krantz, Continuously varying peaking

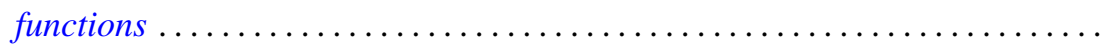

Joseph Leonide Gerver, Long walks in the plane with few collinear points ......

Joseph Leonide Gerver and Lawrence Thom Ramsey, On certain sequences of

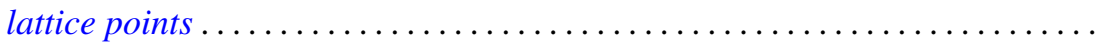

John R. Graef, Yuichi Kitamura, Takaŝi Kusano, Hiroshi Onose and Paul Winton

Spikes, On the nonoscillation of perturbed functional-differential

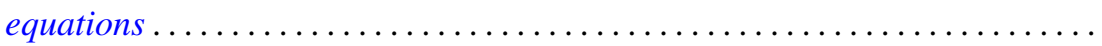

James A. Huckaba and James M. Keller, Annihilation of ideals in commutative

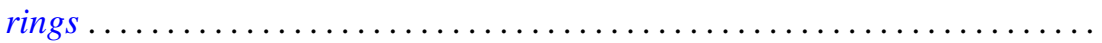

Anzelm Iwanik, Norm attaining operators on Lebesgue spaces . . . . . . . . . . .

Surjit Singh Khurana, Pointwise compactness and measurability . . . .......... 387

Charles Philip Lanski, Commutation with skew elements in rings with

involution.

Hugh Bardeen Maynard, A Radon-Nikodým theorem for finitely additive bounded

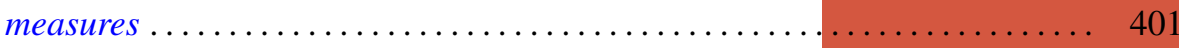

Kevin Mor McCrimmon, Peirce ideals in Jordan triple systems ..

Sam Bernard Nadler, Jr., Joseph E. Quinn and N. Stavrakas, Hyperspaces of compact convex sets.

Ken Nakamula, An explicit formula for the fundamental units of a real pure

sextic number field and its Galois closure ............

Vassili Nestoridis, Inner functions invariant connected components . .

Vladimir I. Oliker, On compact submanifolds with nondegenerate parallel

normal vector fields.

Lex Gerard Oversteegen, Fans and embeddings in the plane.

Shlomo Reisner, On Banach spaces having the property G.L

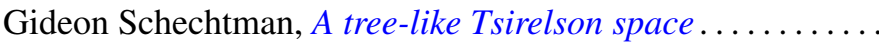

Helga Schirmer, Fix-finite homotopies . . . . . . . . . . . .

Jeffrey D. Vaaler, A geometric inequality with applications to linear forms . .

William Jennings Wickless, $T$ as an $\mathscr{G}$ submodule of $G$.....

Kenneth S. Williams, The class number of $Q(\sqrt{-p})$ modulo 4 , for $p \equiv 3$ (

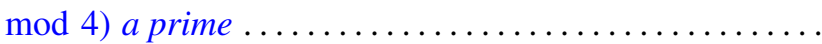

